\title{
Advantages of civilization approach to studying the development of society
}

\author{
Azamat Baymurzaev Dosmurzaevich ${ }^{1}$ \\ ${ }^{1}$ Assistant teacher, department of social sciences, Karakalpak state university named after \\ Berdakh, Nukus city, Karakalpakstan, Uzbekistan \\ Email: ziyonetvilly@gmail.com
}

\begin{abstract}
The article is devoted to one of the problems of the methodology of the social - humanitarian sciences. The author considers the weaknesses of the formation approach in connection with the problem of the "Asian mode of production". It is concluded that the civilization approach allows us to more broadly consider the development of society than the formational approach.
\end{abstract}

Keywords: methodology, science, society, formation, civilization, Asian mode of production.

\section{INTRODUCTION}

One of the main features of science as the best way to know the world is its systematic feature. This sign of knowledge influences realization of its other attributes, such as rationality and justification. If the last 2 signs represent the essence of theoretical knowledge, systematic designation gives the form. Although the form refers to the way in which content is created, that is, the order of linking underlying components, the systematic nature of science is determined by the methodology that determines the direction of new knowledge acquired in research.

Therefore, development of any science depends not only on its richness of content, but also on its strong methodological base. In this case, any science field, during its development, improves and produces data processing techniques.

In addition to the methods developed by specific subjects, there are common theoretical and philosophical methods. One of the main functions of philosophy is to ensure the interdependence of disciplines by developing common methods for science to study of the world. an element.

In other words, for each branch of knowledge, as a system, it is also a part of a larger system as

Therefore, its existence as a system is determined not only by its internal integrity but also by its relationship with other elements of the immense system as an element. We can clearly see the confirmation of our ideas in natural sciences. New methods of learning the world, started with the Renaissance and developed in the new era, have led to development of natural sciences and to their relevance to human activity. That is, science is not only viewed as a manifestation of human creativity, but also as a social institution, a spiritual practice that can have an impact on society, human life, and that is to say, at the end, science has gained the status of power.

In the end of the second half of the $19^{\text {th }}$ century, this rate of development in natural sciences faced challenges when general methodology of studying the world became insufficient. Philosophy, which deals with development of general methodology, was in crisis.

In other words, quantitative and qualitative changes in the content of science were incompatible with the old form. Content requires a change of form as an active start. Philosophy can overcome this crisis by linking the success of dialectical thinking from a materialistic perspective.

As a result, development of natural sciences has accelerated and has not only been associated with human activities, but also been able to surpass it. Excessive development of science has made it not a facilitator for human activities, but even a determinant of technical development.

When it comes to social sciences, it was a bit more difficult to develop a methodology to integrate these disciplines into the system. This is primarily due to the uniqueness of the research subject in social - humanitarian sciences. Secondly, these subjects show that both complexity of subject-matter and subjectivity are affected.

Therefore, development of methodology of social sciences was much later than natural sciences. The problem of bringing the social sciences to the scientific foundation was only achieved by the middle of the $19^{\text {th }}$ century. The formational theory developed by K. Marks and F. Engels was a great success. The 
first success of this theory was that society and man were regarded as the highest stages of matter formation, and that society's laws were a continuation of the laws of nature.

Most importantly, the direction of material production - the most important aspect of society, providing its systematic unity, has been taken as the basis. All the processes, practices and connections that occur in society are analyzed by establishing links between practice and generating relationships. This allows us to explain society, integrity of people, history of society, not as a collection of various events, but as a system based on serious laws. The process of objective development of society, as well as the increasing knowledge of sociological sciences in their subject matter, also places great demands on the methodology that links knowledge. Methodology should be as comprehensive as it contains the increasing content of particular sciences. Increasing number of new scientific facts that do not correspond to the perfect method of understanding create a problematic situation in science.

We can also see this problematic situation, depending on the formational research method. Discussions on the updating formational theory began in social philosophy in the $1990 \mathrm{~s}$ of the $20^{\text {th }}$ century [1].

Currently, there is still debate among Russian scholars about whether formational approach should remain critically updated or a new paradigm be developed instead [2]. Even alternative theories on formational methods have been proposed to the analysis on community development [3]. One of them is civilization research method.

Unfortunately, scientists in Uzbekistan are not paying enough attention to this problem. It makes impact not only in the direction of social philosophy or development of general philosophical science, but also, on the development of all social - humanitarian sciences. We can see the weaknesses of the methodological framework at present in the social - humanitarian sciences, and even in study of social philosophy. As methodological base the works of the President, government decisions and other state programs are considered. Initiatives and programs developed by government agencies truly serve as a direction for research. They serve to ensure the relevance of research to social practice.

However, coherence of the general science with the logic of development, the problems associated with processes under study, are not less important than government contracts. This aspect provides a link between scientific research and this helps to increase the accuracy of research results.

Indeed, now we will try to give our opinions on the question about whether formational approach can help us to analyze changes in society today or whether we should choose a new one.

Undoubtedly, formational theory has made great progress in analyzing social processes, and it is still in high importance.

However, any theory is based on the background of its time, is a part of conditions, developed on the basis of achievements in science. Formational theory is also represented at that time, based on an analysis of processes occurring in the mid- $19^{\text {th }}$ century, mainly in European society. The strength of formational approach is that it is analyzed as a stage in the development of society, that time is relation to earlier stages of community development.

Therefore, the political-economical theory by K. Marks provided an analysis of development of society as a whole. In its turn, the expansion of the object analysis has drawn conclusions as to the next stages of community development. The whole human society was considered as an interconnected whole system.

However, in the $19^{\text {th }}$ century, Europe was less aware of the social structure of the continents outside of it than the present.

Therefore, the main line of human society development has been interpreted in European example, and other continents have been regarded as social organizations far beyond that. We can see this as an example of the problem of "Asian mode of production", which is not solved on the basis of formational approach [4]. Intensive discussions on this problem have doubled, and in both cases the discussions have been related to the need for accurate scientific explanation in specific societies [5].

For the first time, the $30 \mathrm{~s}$ of the $20^{\text {th }}$ century were associated with the evaluation of revolutionary movements in China, and the second time in the $60 \mathrm{~s}$ of the $20^{\text {th }}$ century in connection with the quest for the independence in Africa.

However, these discussions did not lead to sufficient results. The problem with the "Asian mode of production" was that it required the revision of basis of formational approach. This meant that the methodological framework for whole social sciences would be changed.

According to K. Marks, lack of private ownership of land and the predominance of social production in Asian nations has not yet led to the emergence of a class society, so we can consider such societies as the transition from the primitive to classical society [6]. As Asian mode of production applies not only to the South East Asian social system, but also to social organizations throughout America, as far as East, South Africa and Columbus, based on a formational approach, all continents outside Europe dominated for only $2.5-3,000$ years during the transition from the initial stage of development to the 
classical, and during that time Europe has been able to go through three formations. These countries are much larger than Europe, both in terms of their territory and number of people living there.

In our view, it is a mistake to exclude large parts of the world from historical processes, to relate development of human society with one region.

Today, in Japan and Korea, the processes taking place in China, their transformation into world leaders in many ways, cannot be explained only by the influence of capitalist relations in Europe, development of technology has played a significant role in development of its own social relations, which have been increased for thousands of years in these countries. The problem of Asian mode of production cannot be solved within the formational approach. This is because the formational approach considers social development as a one-way process. This is one of its fundamentals. This formational approach through this principle aims to explain the cohesion of community development.

However, when we look at the theory of local civilization, which is an alternative to the formational approach, we can see that even these theories overlap cultural identity of different regions, they fail to reveal the interconnectedness of cultures and civilizations. In that case, this view leads to unilateralism.

The solution to this problem, in our view, may be related to the application of a civilization research method that analyzes the development of society. This is because the method of civilization research promotes principle of diversity and interdependence in the analysis of community development. Different regions live according to their natural and objective historical development conditions.

Although it is difficult to demonstrate such integrity in the early stages of community development, the following stages are seen as strengthening ties between different regions and development of the entire human community. Through the term civilization, the basis of these relations is social organization of society, the development of society is considered as the complication of this social organization. This approach allows for a more comprehensive consideration at the development of society. The method of civilization research divides society into pre-civilization, agricultural civilization, industrial civilization, and emerging message civilization. Different regions have different social structures under the influence of natural and human factors, all of which reflect the level of development of human society.

\section{CONCLUSION}

Thus, the method of civilization research implies departure of a man from the biological basis as a measure of community development. These social processes allow us to link human issues and analysis of cultural problems.

\section{REFERENCES}

1. Formations or civilizations? (Materials of the "round table")// Questions of philosophy. 1989. No 10. p:36-37;

2. Buzgalin A.V. Civilization approach and the "failures" of Marxism: Man and culture. Questions of philosophy. 2014. No. 11. p:3-13;

3. Shevchenko V.N. Civilization approach under the fire of criticism // Questions of philosophy. 2016. No. 2.p: 33-44;

4. Kachanovsky Yu.V. Discussion on the Asian mode of production on the pages of foreign Marxist press // Problems of pre-capitalist societies in the countries of the East. -M., 1971;

5. Nikiforov B.N., K. Marx and F. Engels. On the Asian mode of production // Problems of precapitalist societies in the countries of the East. -M., 1971;

6. Marx K., F. Engels. Op. 2nd ed., Vol. 19, -M.; 1973, p: 404. 